\title{
Hundred Thousand Per Liter
}

National Cancer Institute

\section{Source}

National Cancer Institute. Hundred Thousand Per Liter. NCI Thesaurus. Code C105490.

A concentration unit expressed as a number or quantity of objects in hundred thousands per unit of volume equal to one liter. 